\title{
Income Distribution and Terms-of-Trade under Generalized Returns to Scale and Capital Accumulation: Implications Using Classical Equilibrium Condition
}

\author{
William Darity' ${ }^{1}$ Bidisha Lahiri² \\ ${ }^{1}$ Sanford School of Public Policy, Duke University, Durham, NC, USA \\ ${ }^{2}$ Department of Economics, Oklahoma State University, Stillwater, OK, USA \\ Email: william.darity@duke.edu,bidisha.lahiri@okstate.edu
}

How to cite this paper: Darity, W. and Lahiri, B. (2019) Income Distribution and Terms-of-Trade under Generalized Returns to Scale and Capital Accumulation: Implications Using Classical Equilibrium Conditio. Theoretical Economics Letters, 9, 2526-2549.

https://doi.org/10.4236/tel.2019.97160

Received: September 16, 2019

Accepted: October 8, 2019

Published: October 11, 2019

Copyright $\odot 2019$ by author(s) and Scientific Research Publishing Inc. This work is licensed under the Creative Commons Attribution International License (CC BY 4.0).

http://creativecommons.org/licenses/by/4.0/

\begin{abstract}
This paper examines the implications of generalized returns to scale on the long-period equilibrium in an economy with 2 goods and 2 inputs where one of the inputs is a produced means of production. The Classical definition of long-period equilibrium defined by profit rates being equalized across sectors is used for closure. The model is initially characterized for a closed economy and then extended to a flexible-wage-North and surplus-labor-South model of trade where the North produces only capital and the South produces the consumption good using Northern capital. Neither full employment in the North nor balanced-growth of the integrated economy emerges under non-constant returns to scale. We characterize income distribution between labor and capital and movements of terms-of-trade between North and South.
\end{abstract}

\section{Keywords}

Generalized Returns to Scale, Surplus, Produced Means of Production, North-South Trade

\section{Introduction}

The assumption of constant returns to scale is common in the analysis of the evolution and steady state of economies, while increasing returns to scale is modelled by assuming that the economies of scale are external to the firm, implying that the firms still earn zero profit in equilibrium. The classical condition of long-period equilibrium defined as profit rates being equalized across sectors 
through inter-sectoral mobility of capital is thus an obvious candidate to model non-constant returns to scale where firms earn profit in equilibrium. According to [1] "Anyone accustomed to think in terms of the equilibrium of demand and supply may be inclined, on reading these pages, to suppose that the argument rests on a tacit assumption of constant returns in all industries ... In fact, however, no such assumption is made."

The Classical approach is different from the Neoclassical microeconomic theory, where if the firm or the industry displays positive profits for a sustained period of time, they are attributed to imperfections in the operation of the market and, thus, to departures from competition. The Classical equilibrium is consistent with a positive rate of profit that is equalized in the longer horizon, under a wider definition of dynamic competition. Under the Classical approach, the existence of competition simply means sufficient factor mobility (or mobility of capitalists) to establish a tendency toward long horizon profit rates being equalized across industries, without making any prior commitment to the market structure attributes of industries and/or firms. It is especially suitable for accommodating generalized returns to scale. "...investigation is concerned exclusively with such properties of an economic system as do not depend on changes in the scale of production or in the proportion of factors" [1].

The Classical system also treats natural prices as centers of gravitation that the economy approaches in the long run: observed market prices, arising due to the interaction of supply and demand, are short-term deviations around the long-term Classical natural prices. In the Classical paradigm, capitalists engage in mark-up pricing irrespective of market structure and return to scale, resulting in departure from the marginal value payment to inputs ${ }^{1}$. Surplus product remains after all input costs have been deducted from gross outputs and a uniform rate of profits obtains in conditions of free competition. This surplus approach is used in the current paper to characterize income distribution. The standard trade theory economy with no surplus can be retrieved easily as a special case by examining the circumstances where markups are zero.

In the absence of the marginal product theory of payment to inputs, the contribution of this paper is to analyze income distribution between labor and capital in the context of closed and open economies through the use of the Classical closure condition when surplus exists in the long-period equilibrium under generalized returns to scale assumption. The capital stock is endogenous to the model with investment being a function of the Classical long period profit rates. The outcome is the characterization of a long period equilibrium where most of the variables or their growth rates do not remain steady, leading to the distinction of the concept of long-period equilibrium from steady state equilibrium [2] [3] [4] [5] [6]. The common characterization of the Neo-classical steady state with a zero profit outcome is replaced by a uniform but positive profit outcome of long period equilibrium in the Classical characterization due to the continued ${ }^{1}$ In real world situations, whether an industry is perfectly competitive or not, rarely are workers paid the full value of the marginal product. 
existence of surplus arising from mark-up pricing. Positive profit provides incentive for continued capital accumulation by capitalists driving endogenous growth in the long horizon even without any assumption of technological change.

Since capital stock is endogenous, the current paper does not seek to contribute to the factor-endowment driven trade models. Instead, in the open economy setting the North is characterized as a full-employment economy that only produces capital goods using domestic labor and capital as also in [7], although we abandon the assumption of constant returns to scale and the associated outcome of price of capital equaling the value of its marginal product. The South is a [8] type surplus labor economy that produces food using domestic labor and capital from North as inputs. While the model is similar to that of [9], the relaxation of the assumption of constant returns to scale leads to several interesting results through the use of the Classical long period equilibrium condition in a North-South setting with generalized returns to scale and the presence of pure profits ${ }^{2}$.

The remainder of the paper is organized as follows: Section 2 provides a review of the existing literature while Section 3 considers the implications of non-constant returns to scale for a closed economy under Classical long period equilibrium with capital accumulation. In Section 4, the model is extended to an open economy setup similar to the structurally asymmetric North-South model of trade of [9]. Concluding observations are summarized in Section 5.

\section{Literature Review}

Our paper applies the Classical concept of long-period equilibrium with capital accumulation to incorporate non-constant returns to scale and then extends the model to asymmetric North-South trade. Hence the literature review discusses the three topics that our paper seeks to bring together: Classical equilibrium, generalized returns to scale and asymmetric North South trade with capital accumulation (Figure 1).

Classical Equilibrium (Section 2a)

(Existence of surplus under constant and non-constant returns to scale) (Existence of surplus under competitive and non-competitive market structure)

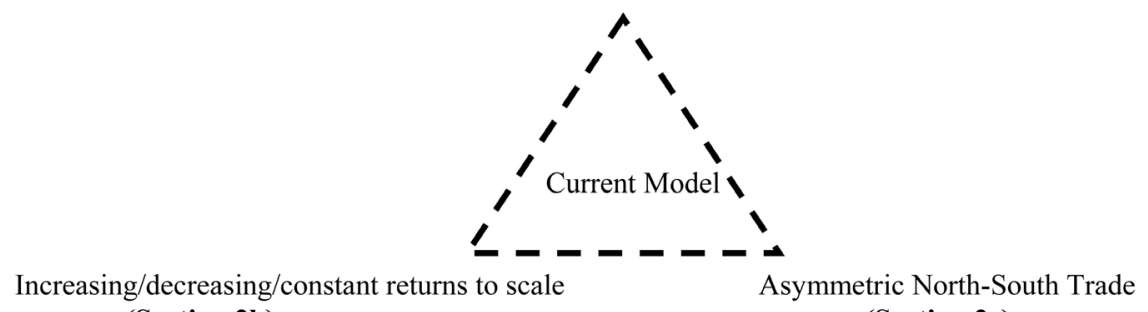

(Section 2b)

(Section 2c)

Figure 1. Contribution of current paper.

${ }^{2}$ While there are real world exceptions to the above modelling framework, some of those exceptions might be driven partially by government policy incentives, the fact that some countries cannot be neatly classified into North-South categories, or by endogenous technological growth. The latter is not a focus of our current model but might be incorporated into a future version. 


\subsection{The Classical Concept of Long-Period Equilibrium}

We adopt the Classical approach to long-period equilibrium for our model of generalized returns to scale. Here market prices in the long-horizon gravitate towards the production costs, and fluctuations around production prices appear in the short run due to demand or other shocks to the system. The Classical equilibrium is characterized by equalization of profit rates across sectors. This requires the ability of capital to flow freely across sector until all profit rates become uniform.

[10] argues that the Classical equalization of profit works under a broader definition of competition, for example barriers to entry resulting in oligopoly have temporary effects which are resolved in the long run leading to gravitation of market prices toward production prices and equalization of profits across industries. Hence Semmler finds that the prospect of profit rate equalization does not require a particular market structure, with the exceptions of few extreme cases such as natural monopolies created due to control of scarce resources or artificial monopolies.

[11] [12] view of the multi-product, multi-divisional corporation as a decision making body leads to the equalization of profit rates across industries independent of the degree of intra-industry competition. Hence short-run demand shocks resulting in higher market prices result in an expansion of the sector, yielding a movement back toward production prices. Thus Clifton's interpretation also finds that the Classical/Sraffian approach to competition is applicable under more general market structure than the orthodox concept of competition.

[13] discusses the problems of existence and stability of the Classical equilibrium. He points out that when market prices differ from production prices, there is not a sufficient mechanism to ensure that the adjustment process will gravitate toward the long run equilibrium especially if firms within an industry have different techniques of production or if the technology itself is changing over time making the long period equilibrium a moving target. Several defenders of the Classical concept of long-period equilibrium have tackled the question of existence and stability using newer and extended interpretations of the steady state profits, of which [14] and [15] are discussed below.

[14] asserts the validity of Classical equalization of profit since corporations will contract their activities in industries which are expanding slower than the economy on average and move into sectors that are growing faster. In this setup, market prices, instead of being signals to expand, are instead outcomes determined by the desired rate of growth coupled with short run demand shocks. [15] views the Classical concept of dynamic competition as bringing realism to the Neoclassical static concept of perfect competition. The Classical dynamic conception of competition is a process of rivalry between firms in their incessant struggle to increase their market share by raising productivity and reducing unit cost-and by undercutting prices leading to a gradual displacement and subsequent absorption, or, simply, the elimination of rival firms. This concept re- 
mains relevant for other types of market structures such as monopolistic competition and oligopoly.

The above literature examines the Classical equilibrium under constant returns to scale. We extend the application of the Classical closure to generalized returns to scale using a formal mathematical exposition. ${ }^{3}$ The Classical concept of long period equilibrium discussed above, with profits being equalized across sectors in the long horizon due to entry and exit of firms and expansion and contraction of firm, is adopted for closure of the current model.

\subsection{Generalized Returns to Scale and the Effect of Trade on Returns to Labor}

[16] and [17] find evidence of scale efficiency at the decision-making-unit or firm level, suggesting the necessity for theoretical research that models variable returns to scale that are internal to the firms. [18] incorporates increasing returns by allowing input-output ratios to vary with the scale of output. [19] rank equilibria in terms of welfare when variable returns to scale are internal to the firms. But both the [18] and [19] investigations assume that even under non-constant returns to scale, perfect competition prevails in the special sense that the exchange value of all output is exactly equal to the sum of the factor payments. In all of this research, then, there is no outright surplus. ${ }^{4}$

[21] explore the trade implications of factor endowment model with increasing returns to scale in one industry while [22] studies markups under constant returns to scale under oligopoly: in both papers the limited number of firms does not drive profits to zero.

An important direction of contemporary trade theory is to model heterogeneous firms that experience increasing returns to scale. Hence a surplus exists at the firm level for the more efficient firms. In [23] trade causes the less efficient firms to exit the market, while the more efficient firms survive, participate in the export market and experience an increase in profits. [24] also allow for variable markups using a system of monopolistically competitive heterogenous firms faced with a linear demand system; this causes the mark-up of each firm to depend on the number and average productivity of the competitive firms. [25] empirically demonstrate that the more productive firms charge a higher markup and the mark-up increases when these efficient firms enter the export market. The income distribution aspect of international trade in models with heterogeneous firms is explored in [26] [27] [28] [29]. [30] introduce the concept of traded intermediate inputs in the heterogeneous firm model.

However, the studies above focus on single industries, instead of the general equilibrium approach adopted in our model. [31] set up a general equilibrium model with heterogeneous firms though capital is not included as a factor of ${ }^{3}$ We build on [18] for characterization of generalized returns and on [9] for characterization of North-South asymmetries and extend their baseline models to incorporate Classical equilibrium condition.

${ }^{4}[20]$ provide a useful survey of this strand of theoretical literature that explores variable returns to scale. 
production. [32] consider a decreasing cost and a constant cost industry, where they deploy the conjectural variation to allow variations in market structure. By ignoring capital flows, both these models have no channel for the profits to be equalized across industries in the long horizon.

\subsection{Asymmetric North-South Trade with Capital Accumulation}

[33] develop a dynamic model of trade under constant returns to scale assumption, where investment good produced in a given period can be used as capital input in the next period similar to our model. This model has been extended in various forms to study dynamic models of trade with capital accumulation: [34] considers implications of trade when intertemporal rate of time preference is different across countries, [35] considers intertemporal optimization and fiscal policy implications, [36] introduce externalities with constant returns to scale in an endowment driven trade model to predict multiple balanced growth paths. All these model consider constant returns to scale and perfect competition.

[37] provide an exhaustive survey of North-South modelling possibilities arising out of structural asymmetries. Since government policy implications, endogenous knowledge models or consumption imitation effects are not the focus in our current exercise, [9] serves as a suitable starting point ${ }^{5}$. It allows us to focus on how variations in the returns to scale play out in the context of structural asymmetries in the North and South. However the Findlay model assumes zero international capital mobility with the stock of Southern capital determined by past history. [38] and [39] and [40] are important precursors to our model as they incorporate international capital mobility into the Findlay framework with the North being the exporter of capital in the open economy. Instead of constant returns to scale assumed in these papers, we adopt a more generalized return to scale formulation leading to the possibility of a surplus, with rates of profit equalized under the Classical long period definition of equilibrium.

In contrast, [41] considers the interaction of two economies both with symmetric structures, both growing in Solow fashion. His primary interest is the effect of capital flows on wages. He finds that the capital exporting economy experiences a reduction of domestic wages.

[42] provides an elegant model that incorporates capital accumulation in the standard two sector model used by [43]. He studies comparative dynamics of the single open economy under different scenarios of closure from the perspective of a single open economy that include conditions of constant capital-labor ratio, constant savings rate and constant profit rate. This last condition comes closest to our formulation of closure. However, Smith imposes the condition of the same profit rate applying in autarky and in trade, while we explore same equilibrium profit rates in the North and South economy when each economy produces one of the commodities.

[44] consider increasing returns to scale in the traded goods sector with a ${ }^{5}$ Please refer to [37] for an overview of the literature capturing the diverse North-South trade modelling approaches. 
non-traded goods sector experiencing a constant or decreasing returns to scale while in [45] both sectors' goods are traded. The first paper finds that trade liberalization might lead to instability producing a dynamic contraction of the capital stock while the latter paper finds that the desirability of openness in terms of capital accumulation and growth depends on the level of development prior to the beginning of trade.

The results in each of the above models depend on the type of returns to scale assumed in the model. We build a model that is applicable to generalized returns to scale, and we do so by focusing on the profit rates prevailing in each sector, an important consideration also missing in previous inquiries.

\section{Closed Economy Classical Equilibrium with a Capital-Goods Sector}

In this section we set up the $2 \times 2$ framework where one of the two factors is a produced means of production. The produced input is assumed to be homogenous capital. Our concern here is not the implications of capital heterogeneity issue for the pure trade theory, which, in and of itself, a major area of research. Many of these papers are collected in [46] [47].

We use some features of the Solow growth model as a starting point for the North though we abandon the constant returns to scale assumption, while a fixed-wage surplus-labor model characterizes the South with the terms-of-trade being determined jointly between them.

The two homogenous factors: the primary input labor $L$ and the produced input capital stock from last period $K_{-1}$ are used to produce the two outputs food $F$ and the capital good $K$. The capital good is only used for production purposes, while food represents the sole consumption commodity in this model. ${ }^{6}$ The technological structure of the economy can be displayed readily in the following activity analysis format ${ }^{7}$.

$$
\left(\begin{array}{cc}
a_{K K} & a_{K F} \\
a_{L K} & a_{L F}
\end{array}\right)\left(\begin{array}{c}
K \\
F
\end{array}\right)=\left(\begin{array}{c}
K_{-1} \\
L
\end{array}\right)
$$

Each $a_{i j}$ is the input-output coefficient for activity $j$ (where $j=K, F$ ). All equations are relevant for time period $\mathrm{t}$, the subscript is dropped for simplicity.

Following [48], firms are assumed to set price as a mark-up on their costs: the workers receive wages, consume the consumption good but do not save while the capitalists decide production, receive profits, and use this profit income for consuming the consumption commodity and making investments. The price of the produced means of production $P_{K}$ will be treated as numeraire throughout. ${ }^{8}$ The price equations for this system, assuming a world where there typically is a ${ }^{6}$ The model is restricted to $2 \times 2$ dimension for computational purposes. Consideration of a produced factor $K$ leaves the model to have only one non-produced primary input L and only one consumption $\operatorname{good} F$.

${ }^{7}$ These are also commonly known as the quantity equations.

${ }^{8}$ If $P_{K}$ is not treated as numeraire but is determined explicitly, there is no qualitative change in the character of the model. Each $a_{i j}$ would be a function not only of the scale of the $i$ th commodity ( $i=$ $K, F)$ but also the ratio of factor prices, $w / P_{K}$. 
pure profit, will take the following form, with the $\gamma_{s}$ s capturing the markup effect.

$$
\begin{array}{ll}
1=\left(a_{L K} w+a_{K K}\right) \gamma_{K}, & \gamma_{K} \geq 1 \\
P_{F}=\left(a_{L F} w+a_{K F}\right) \gamma_{F}, & \gamma_{F} \geq 1
\end{array}
$$

The standard trade theory economy with no surplus can be retrieved easily by examining as a special case the circumstances where markups are zero. Under constant returns-and-cost minimization, the mark-ups $\gamma_{i}$ are equal to one, there is no surplus in the corresponding sector. However the current model is applicable to a wider range of scenarios when $\gamma_{i}$ are larger than one and there is a surplus. No specific assumptions need be made about returns to scale or about market structure as long as capital, whether in the form of new or existing firms, moves in and out of industries in response to differential profit rates. Economies or diseconomies of scale can be viewed as fully internal to firms. The determination and evolution of the markups are endogenous to the model. The prices used in our formulation capture long period prices around which demand driven market prices fluctuate. Long-period prices are dictated by the cost of production. However, in an Increasing returns industry with falling costs, prices may remain steady of may rise if the firm(s) are increasing their markups, while the opposite might hold in a decreasing returns industry.

The rate of profit in each activity is defined as the rate of return over the cost of the capital input. This indicates the profit per unit of capital and captures the rewards from using one unit of capital in any given sector. There will be intersectoral adjustments to capital use as long as the rewards are not equalized. Using the quantity Equation (1) and the price Equations (2)-(3), the rates of profits $(\rho)$ are expressed in terms of the mark-ups $(\gamma)$ as shown in (4)-(5).

$$
\begin{gathered}
\rho_{K}=\frac{K-w L_{K}-K_{K,-1}}{K_{K,-1}}=\left(\frac{\gamma_{K}-1}{\gamma_{K}}\right)\left(\frac{1}{a_{K K}}\right) \\
\rho_{F}=\frac{P_{F} F-w L_{F}-K_{F,-1}}{K_{F,-1}}=P_{F}\left(\frac{\gamma_{F}-1}{\gamma_{F}}\right)\left(\frac{1}{a_{K F}}\right)
\end{gathered}
$$

The profit rate captures two different incentives: a positive rate of profit encourages capitalists to engage in production for investment purposes while unequal rates of profit across sectors provides incentive for capital to flow in and out of the sectors. The prices of the inputs and outputs adjust to equalize rates of profit across sectors in the long-period Classical equilibrium. To close this system, we set the right sides of (4) and (5) equal to each other, hence placing the economy in the Classical long-period equilibrium characterized by equality of profit rates across sectors. Differentiating the logarithm of the above system yields Equation (6) through (10). ${ }^{9}$

$$
\hat{K}+\hat{F}+\hat{a}_{K F}+\hat{a}_{K K}=\hat{K}_{-1}
$$

${ }^{9}$ Hat-algebra, popularized by [43], defines $\hat{K}=\frac{d K}{K}$. 


$$
\begin{gathered}
\lambda_{L K} \hat{K}+\lambda_{L K} \hat{a}_{L K}+\lambda_{L F} \hat{F}+\lambda_{L F} \hat{a}_{L F}=\hat{L} \\
\lambda_{L K} \equiv \frac{L_{K}}{L}, \lambda_{L F} \equiv \frac{L_{F}}{L}, \quad \lambda_{L K}+\lambda_{L F}=1 \\
\theta_{K K} \hat{a}_{K K}+\theta_{L K} \hat{a}_{L K}+\theta_{L K} \hat{w}+\hat{\gamma}_{K}=0 \\
\theta_{K K} \equiv \frac{a_{K K}}{a_{L K} w+a_{K K}}, \theta_{L K} \equiv \frac{a_{L K} w}{a_{L K} w+a_{K K}}, \quad \theta_{K K}+\theta_{L K}=1 \\
\theta_{K F} \hat{a}_{K F}+\theta_{K F} \hat{a}_{L F}+\theta_{L F} \hat{w}+\hat{\gamma}_{F}=\hat{P}_{F} \\
\theta_{K F} \equiv \frac{a_{K F}}{a_{L F} w+a_{K F}}, \theta_{L F} \equiv \frac{a_{L F} w}{a_{L F} w+a_{K F}}, \quad \theta_{K F}+\theta_{L F}=1 \\
\hat{a}_{K F}-\hat{a}_{K K}+R_{K} \hat{\gamma}_{K}-R_{F} \hat{\gamma}_{F}=\hat{P}_{F} \\
R_{K} \equiv\left(\frac{1}{\gamma_{K}-1}\right) ; \quad R_{F} \equiv\left(\frac{1}{\gamma_{F}-1}\right)
\end{gathered}
$$

Equation (6) and Equation (7) are the logarithmic change versions of the quantity equations represented by Equation (1). Equation (8) and Equation (9) are the logarithmic change versions of the price equations. Equation (10) is the logarithmic change version of the long-period equilibrium condition that sets rates of profit equal between the two sectors and correspondingly sets their percentage rates of change equal as well, i.e., $\hat{\rho}_{K}=\hat{\rho}_{F}$.

With $P_{K}$ as numeraire, each input-output coefficient can be treated as varying in response to the level of output and the wage rate ${ }^{10}$.

$$
\begin{aligned}
& a_{K K}=a_{K K}(K, w) \\
& a_{L K}=a_{L K}(K, w) \\
& a_{K F}=a_{K F}(F, w) \\
& a_{L F}=a_{L F}(F, w)
\end{aligned}
$$

The logarithmic change versions of the input-output Equation (11) through (14) are captured by Equation (15) through (18).

$$
\begin{gathered}
\hat{a}_{K K}=\varepsilon_{K}^{K K} \hat{K}+\varepsilon_{w}^{K K} \hat{w} \\
\hat{a}_{L K}=\varepsilon_{K}^{L K} \hat{K}+\varepsilon_{w}^{L K} \hat{w} \\
\hat{a}_{K F}=\varepsilon_{F}^{K F} \hat{F}+\varepsilon_{w}^{K F} \hat{w} \\
\hat{a}_{L F}=\varepsilon_{F}^{L F} \hat{F}+\varepsilon_{w}^{L F} \hat{w}
\end{gathered}
$$

The above method of representing changes in the input coefficients as functions of factor prices and the scale of production is similar to [18]. Each elasticity $\varepsilon_{j}^{i j}$ captures the scale effects and each elasticity $\varepsilon_{w}^{i j}$ captures the substitution effect. When the $\varepsilon_{j}^{i j}$ s are positive, decreasing returns prevail; when they are negative, increasing returns prevail; and when they are zero, technologies possess constant returns to scale. If the $\varepsilon_{w}^{i j}$ s are nonzero, substitutability exists between capital and labor; when they are zero, there are no possibilities of subs-

${ }^{10}$ Under constant returns to scale, the input-output coefficients vary only with changes in factor prices but not with changes in the output level. 
titution between the factors.

Mayer assumed that the returns of scale are external to the firm and, hence, exchange value equals factor cost of production, making profits zero. The contribution of the current paper is to allow for the existence of profits by making returns to scale considerations internal to the firms and combining this with Mayer's method of modelling generalized returns to scale.

Notice that the markup must be determined endogenously in this framework and must adjust with a change in either relative price or the rate of growth of the national labor force. With the price of capital goods as numeraire, variations in the price of food indicate the direction of change of the relative price between manufactures and food. The "endowment" of the capital good is determined endogenously in this Classical long period equilibrium. With capital accumulation, we find below that the employment of labor is determined endogenously.

Given that we are analyzing the long period equilibrium, it is reasonable to assume that during the transitional period capital is endogenously determined though accumulation. As in conventional models, investment (i.e. $d K$ ) is driven by the rewards of capital allocation in the given activity (i.e. profit), or that the percentage change in capital is an increasing function of the profit rate as shown in Equation (19). ${ }^{11}$

$$
\hat{K}=I(\rho), \quad I^{\prime}>0
$$

The long-period equilibrium version of Equation (19), as defined by Classical closure relevant for our analysis, is where sectoral profit rates have stabilized at the uniform, general profit rate $\rho^{*}$. This means in turn that capital accumulation must proceed at a constant rate $\hat{K}^{*}$ consistent with the long-period general profit rate. However, the growth rates of all other variable do not emerge to be constant as in standard growth model ${ }^{12}$.

Under the long-period condition that $\hat{\rho}_{K}=\hat{\rho}_{F}=0$ and $\hat{K}^{*}=$ constant, solution of the model of this section of the paper necessitates dropping the full employment assumption. Wage flexibility does not, in this case, guarantee full employment. $\hat{L}$ must now be determined endogenously. This implies that given exogenous growth of the labor force and endogenously determined employment, there can be less than full employment even in long-term equilibrium. ${ }^{13}$ So Equation (6) through (10), and (19) represents six equations in six unknowns: $\hat{L}, \hat{F}, \hat{P}_{F}, \hat{w}, \hat{\gamma}_{K}$, and $\hat{\gamma}_{F}$. The solution to this system is provided in below.

$$
\hat{\gamma}_{K}^{*}=\frac{\left\{\left(\theta_{L K} \varepsilon_{K}^{L K}+\theta_{K K} \varepsilon_{K}^{K K}\right)-\left(\theta_{L K} \varepsilon_{w}^{L K}+\theta_{K K} \varepsilon_{w}^{K K}+\theta_{L K}\right) \frac{\varepsilon_{K}^{K K}}{\varepsilon_{w}^{K K}}\right\} \hat{K}^{*}}{\left\{\left(\theta_{L K} \varepsilon_{w}^{L K}+\theta_{K K} \varepsilon_{w}^{K K}+\theta_{L K}\right) \frac{R_{K}}{\varepsilon_{w}^{K K}}+1\right\}}
$$

\footnotetext{
${ }^{11}$ The function $I(\rho)$ can be interpreted either as an investment function or as a saving function where all saving is from pure profit income. We assume zero depreciation.

${ }^{12}$ In other words, only $\hat{K}^{*}$ is time invariant. The growth rates of all other variables changes over time. ${ }^{13}$ This can be equivalently interpreted as the labor supply being endogenous and adjusting to labor demand in the long run in a Classical framework.
} 


$$
\begin{gathered}
\hat{w}^{*}=\left(\frac{R_{*}}{\varepsilon_{W}^{K K}}\right) \hat{\gamma}_{K}^{*}-\left(\frac{\varepsilon_{K}^{K K}}{\varepsilon_{W}^{K K}}\right) \hat{K}^{*} \\
\hat{F}^{*}=\left(\frac{1-A \varepsilon_{K}^{K K}}{1+\varepsilon_{F}^{K F}}\right) \hat{K}^{*}+\left(\frac{A \varepsilon_{W}^{K K}+\varepsilon_{W}^{K F}}{1+\varepsilon_{F}^{K F}}\right)\left(\frac{\varepsilon_{K}^{K K}}{\varepsilon_{W}^{K K}}\right) \hat{K}^{*}-\left(\frac{A \varepsilon_{W}^{K K}+\varepsilon_{W}^{K F}}{1+\varepsilon_{F}^{K F}}\right)\left(\frac{R_{K}}{\varepsilon_{W}^{K K}}\right) \hat{\gamma}_{K}^{*} \\
\hat{L}^{*}=\lambda_{L K}\left(1+\varepsilon_{K}^{K K}\right) \hat{K}^{*}+\lambda_{L F}\left(1+\varepsilon_{F}^{L F}\right) \hat{F}^{*}+\left(\lambda_{L K} \varepsilon_{W}^{L K}+\lambda_{L F} \varepsilon_{W}^{L F}\right) \hat{w}^{*} \\
\hat{\gamma}_{F}^{*}=\left(\frac{1}{1+R_{F}}\right)\left\{R_{K} \hat{\gamma}_{K}^{*}-\varepsilon_{K}^{K K} \hat{K}^{*}+\left(\varepsilon_{F}^{K F}-\theta_{L F} \varepsilon_{F}^{L F}-\theta_{K F} \varepsilon_{F}^{K F}\right) \hat{F}^{*}\right. \\
\left.+\left(\varepsilon_{W}^{K F}-\varepsilon_{W}^{K K}-\theta_{L F} \varepsilon_{W}^{L F}-\theta_{K F} \varepsilon_{W}^{K F}-\theta_{L F}\right) \hat{w}^{*}\right\} \\
\hat{P}_{F}^{*}=\left(\theta_{L F} \varepsilon_{F}^{L F}+\theta_{K F} \varepsilon_{F}^{K F}\right) \hat{F}^{*}+\left(\theta_{L F} \varepsilon_{W}^{L F}+\theta_{K F} \varepsilon_{W}^{K F}+\theta_{L F}\right) \hat{w}^{*}+\hat{\gamma}_{F}^{*}
\end{gathered}
$$

From (20) and (24), it is evident that although the profit rates are uniform and stable, the markups must change continuously to preserve long-period equilibrium. It is ambiguous whether they rise or fall continuously in long-period equilibrium; it depends upon the specific parameterizations. But there are necessarily bounds on the values that $\gamma_{M}$ and $\gamma_{F}$ can take since they can never fall below unity and can never reach infinity. Presumably the bounds must be fixed even more tightly by institutional considerations or by the struggle over factor shares between, say, workers and profit recipients.

The wage rate in this economy [see (21)] is always driven upward by a rise in the markup in the capital goods sector. Given that the price of capital is normalized to one, this change in wage entails a real gain to labor. The rise in the price of $\mathrm{K}$ goods pushes up the demand for labor, which, in turn, raises its price. The wage also is driven upward by a higher rate of capital goods production under increasing returns to scale and driven downwards when returns are diminishing.

Under IRS input requirements fall with increased production; hence, given the prevailing mark-up, payments to per-unit labor go up and vice-versa under decreasing returns to scale. There is no effect of capital accumulation on the wage rate under constant returns to scale in the capital goods sector.

Here there is always an inverse relationship between movements in the wage rate and employment, regardless of the conditions of scale. Growth in employment [see (23)] is positively related to capital accumulation and expanded food production under diminishing or constant returns. The positive relationship can be maintained under increasing returns as long as, again, the economies of scale are not "too large," i.e., as long as $\left(1+\varepsilon_{K}^{L K}\right)$ and $\left(1+\varepsilon_{F}^{L F}\right)$ are both positive.

Figure 2 provides an intuitive explanation of this condition. Increasing returns to scale represent a negative relationship between the labor coefficient and the output level. A rectangular hyperbola which has an elasticity of negative one $\left(\varepsilon_{K}^{L K}=-1\right)$ represents a special case of increasing returns where ceteris-paribus, the decrease in per-unit labor requirement triggered by an increase in production keeps the employment level unchanged as seen by comparing the areas $Q_{j} a_{j}^{i j}$ at various coordinates along the solid locus.

If increasing returns are weaker, i.e. the labor coefficient locus is flatter than a 


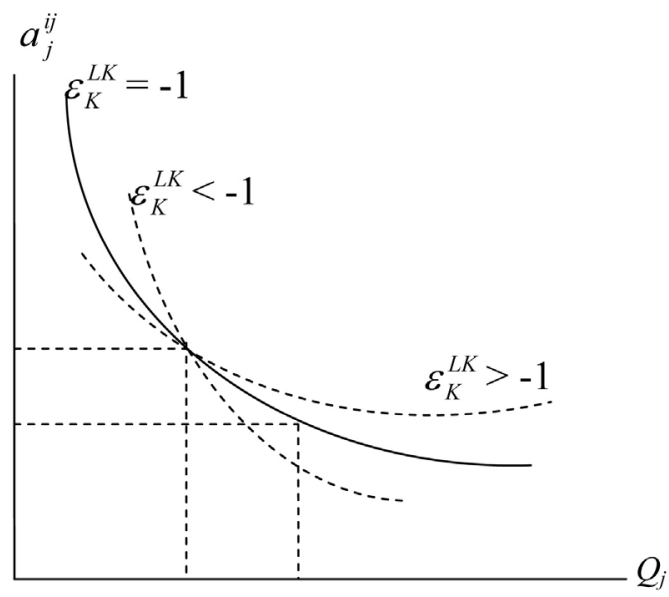

Figure 2. Partial effect of production on employment under increasing returns to scale.

rectangular hyperbola (and $\varepsilon_{K}^{L K}>-1$ ), then an increase in production increases employment. If increasing returns are stronger. i.e. the labor coefficient locus is steeper than a rectangular hyperbola (and $\varepsilon_{K}^{L K}<-1$ ), then an increase in production actually decreases the employment. This is never the case with decreasing or constant returns as shown in Figure 3, where an increase in production invariably corresponds to an increase in employment $Q_{j} a_{j}^{i j}$.

The terms of trade between food and manufactures $P_{F}$, improves with greater food production under diminishing returns but deteriorates under increasing returns. There is no effect of expanded food output on the terms of trade when returns are constant. A higher markup in the food sector unambiguously raises the food terms of trade. However, an increase in the wage rate has an ambiguous effect on the food terms of trade; it depends upon the relative magnitudes of the elasticities of the input-output ratios in food production and the corresponding shares of the factors in food costs.

Notice also the recursive nature of this system. Everything ultimately is driven by the rate of capital accumulation $\hat{K}^{*}$, which in turn is governed by the general rate of profit that prevails in the long period. In fact, with constant returns to scale in both sectors, even without the assumption of cost minimization, the system resembles nothing more than a two-sector [7] model where balanced growth prevails. ${ }^{14}$

\section{Classical Equilibrium in North-South International Trade Framework}

It is a short step from the closed economy model in Section 3 to a further ${ }^{14}$ Under constant returns, $\varepsilon_{K}^{L K}=\varepsilon_{K}^{K K}=0$, which means $\hat{\gamma}_{K}^{*}=0$ from (B1). This means in turn that $\hat{w}^{*}=0$. The rate of growth of food output must be identical with the steady-state rate of growth of the capital stock, or $\hat{F}^{*}=\hat{K}^{*}$. This implies, in turn, that employment growth proceeds at a rate such that $\hat{L}^{*}=\left(\lambda_{L K}+\lambda_{L F}\right) \hat{K}^{*}$. If the rate of capital accumulation departs from the full employment rate, the term $\left(\lambda_{L K}+\lambda_{L F}\right)$ will be less than unity and employment growth will be slower than the capital stock growth rate. If by chance $\hat{K}^{*}$ is the full employment growth rate, then the economy grows in Solow-smooth fashion with $\hat{L}^{*}=\hat{F}^{*}=\hat{K}^{*}$. 


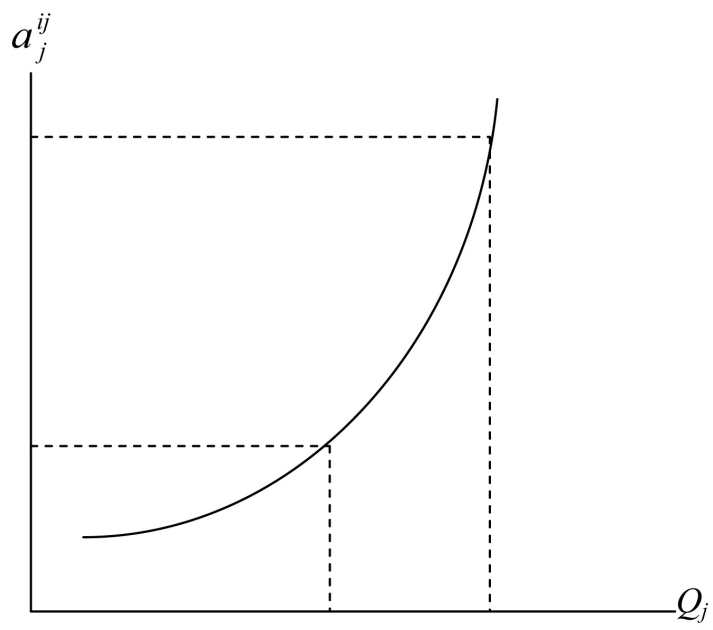

Figure 3. Partial effect of production on employment under decreasing and constant returns to scale.

modification to derive a North-South (or MDC-LDC) model of trade of the type developed by [9]. He postulated that the North was a [7] type full-employment economy that only produced capital goods using domestic labor and capital, and the South was a Lewis (1954) surplus labor economy that produced food using domestic labor and capital from North as inputs. He then inquired about the consequences of trade between them.

In this setting, national boundaries exist between the manufacturing and food sectors, so that labor is no longer transferable between activities. In the North, there is Solovian full employment; in the South, there is a fixed real wage measured in food and "unlimited labor." One of the objectives in North-South trade models is to determine the equilibrium terms of trade: neither country is "small."

The objective of the current model is to allow for the more general case of production under a positive surplus using the Classical equilibrium condition, going beyond the commonplace assumption of constant returns to scale with a zero surplus (Table 1).

$$
K=a_{K K} K+a_{K F} F
$$

Equation (26) is a quantity equation that simply says that capital produced in North is used both in the North to produce itself and in the South to produce food.

$$
\begin{aligned}
& L_{K}=a_{L K} K \\
& L_{F}=a_{L F} F
\end{aligned}
$$

Equation (27) links Northern employment, $L_{K}$, to the volume of production of $K$-goods while Equation (28) says Southern employment, $L_{F}$, is linked to the volume of production of food. Although labor is immobile internationally, capital is highly mobile.

$$
P_{K}=1
$$


Table 1. Notations used in the long-period north-south trade model.

\begin{tabular}{ccc}
\hline$K$ & $=$ & capital-goods (North) \\
$F$ & $=$ & food (South) \\
$L_{K}$ & $=$ & labor in capital goods sector (North) \\
$L_{F}$ & $=$ & labor in food sector (South) \\
$P_{K}$ & $=$ & price of capital goods (numeraire) \\
$P_{F}$ & $=$ & price of food \\
$a_{K K}$ & $=$ & capital-output ratio in capital goods sector \\
$a_{L K}$ & $=$ & labor-output ratio in capital goods sector \\
$a_{K F}$ & $=$ & labital-output ratio in food sector \\
$a_{K F}$ & $=$ & fixed real wage in food sector (South) \\
$\bar{W}_{F}$ & $=$ & wage in capital goods sector (North) \\
$W_{K}$ & $=$ & wage in food sector (South) \\
$W_{F}$ & $=$ & rate of profit in capital goods sector (North) \\
$\rho_{K}$ & $=$ & rate of profit in food sector (South) \\
$\rho_{F}$ & $=$ & markup in capital goods sector (North) \\
$\gamma_{K}$ & $=$ & markup in food sector (South) \\
$\gamma_{F}$ & $=$ &
\end{tabular}

Equation (29) indicates that capital goods serve, again, as numeraire, while Equation (30) and Equation (31) are the Northern and Southern price equations, respectively, both permitting a surplus to exist in excess of factor payments. $P_{F}$ is the terms of trade.

$$
\begin{aligned}
& 1=\gamma_{K}\left(a_{K K}+a_{L K} w_{K}\right) \\
& P_{F}=\gamma_{F}\left(a_{K F}+a_{L F} w_{F}\right)
\end{aligned}
$$

The fixed real wage in the South is displayed in Equation (32).

$$
\bar{w}_{F}=w_{F} / P_{F}
$$

Equation (33) and Equation (34) are the profit rates in each region, and Equation (35) is the long-period equilibrium condition. Regional profit rates become uniform at a general (new international) profit rate, $\rho^{*}$.

$$
\begin{gathered}
\rho_{K}=\left(\frac{\gamma_{K}-1}{\gamma_{K}}\right)\left(\frac{1}{a_{K K}}\right) \\
\rho_{F}=P_{F}\left(\frac{\gamma_{F}-1}{\gamma_{F}}\right)\left(\frac{1}{a_{K F}}\right) \\
\rho_{K}=\rho_{F}=\rho^{*}
\end{gathered}
$$

Equation (36) through (39) indicate, again, that input-output coefficients vary with scale and with relative factor prices.

$$
a_{K K}=a_{K K}\left(K, w_{K}\right)
$$




$$
\begin{aligned}
& a_{L K}=a_{L K}\left(K, w_{K}\right) \\
& a_{K F}=a_{K F}\left(F, w_{F}\right) \\
& a_{L F}=a_{L F}\left(F, w_{F}\right)
\end{aligned}
$$

The logarithmic-change transformation of the system appears in Table 2 below. The system is presented after the logarithmic change versions of Equation (36) through (39) have been substituted into the other equations of the system. Also, Northern employment grows at its "natural" rate in [7] fashion, so that $\hat{L}_{K}=g_{N}$.

The essentials of Findlay's original results can be obtained merely by assuming constant returns to scale and cost minimization in both regions. Under these conditions, once again $\gamma_{K}=\gamma_{F}=1$ and $\hat{\gamma}_{K}=\hat{\gamma}_{F}=0$ so that Equation (45) and Equation (46) in Table 2 are irrelevant. With $\hat{\gamma}_{F}=0$ and $\varepsilon_{F}^{K F}=0$ in (44), the equilibrium percentage rate of change of the terms of trade $\hat{P}_{F}$ must be zero. From (43) with $\hat{\gamma}_{K}=0,\left(\theta_{K K} \varepsilon_{K}^{K K}+\theta_{L K} \varepsilon_{K}^{L K}\right)=0$ and $\left(\theta_{K K} \varepsilon_{w}^{K K}+\theta_{L K} \varepsilon_{w}^{L K}\right)=0$ -the latter due to cost minimization-the equilibrium wage rate also becomes a constant since $\hat{w}_{K}=0$.

With $\hat{w}_{K}=0$ under constant returns, it is evident from (41) that the North's output, the capital good, must grow at the North's natural rate, or $\hat{K}=g_{N}$. Similarly, Equation (40) indicates that Southern output must grow at the same rate as Northern output, which in turn implies $\hat{F}=g_{N}$. Finally, (42) indicates that employment growth in the South must proceed at the natural rate of growth in the North.

This is the basic Findlay result: all sectors of the world economy grow at the North's natural rate in the steady state. The original Findlay result is driven by the combined assumptions that there is no variability in returns to scale, and there is cost minimization everywhere.

But the long-period equilibrium condition utilized here of uniform profit rates implies a steady-state value for the terms of trade. Setting the right sides of

Table 2. A Long-period north-south trade model (Logarithmic Change).

$$
\begin{gathered}
\left(1-A \varepsilon_{K}^{K K}\right) \hat{K}-\left(1+\varepsilon_{F}^{K F}\right) \hat{F}-A \varepsilon_{w}^{K K} \hat{w}_{K}-\varepsilon_{F}^{K F} \hat{P}_{F}=0 \\
A \equiv\left(a_{K K} / 1-a_{K K}\right) \\
\left(1+\varepsilon_{K}^{L K}\right) \hat{K}+\varepsilon_{w}^{L K} \hat{w}_{K}=g_{N} \\
\left(1+\varepsilon_{F}^{L F}\right) \hat{F}+\varepsilon_{w}^{L F} \hat{P}_{F}-\hat{L}_{F}=0 \\
\left(\theta_{K K} \varepsilon_{K}^{K K}+\theta_{L K} \varepsilon_{K}^{L K}\right) \hat{K}+\left(\theta_{K K} \varepsilon_{w}^{K K}+\theta_{L K} \varepsilon_{w}^{L K}\right) \hat{w}_{K}+\hat{\gamma}_{K}=0 \\
\theta_{K K} \varepsilon_{F}^{K F} \hat{F}+\left(\theta_{K F} \varepsilon_{w}^{K F}+\theta_{L F}-1\right) \hat{P}_{F}+\hat{\gamma}_{F}=0 \\
\hat{\rho}_{K}=R_{K} \hat{\gamma}_{K}-\varepsilon_{K}^{K K} \hat{K}-\varepsilon_{w}^{K K} \hat{w}_{K} \\
R_{K} \equiv\left(1 / \gamma_{K}-1\right) \\
\hat{\rho}_{F}=\left(1-\varepsilon_{w}^{K F}\right) \hat{P}_{F}+R_{F} \hat{\gamma}_{F}-\varepsilon_{F}^{K F} \hat{F} \\
R_{F} \equiv\left(1 / \gamma_{F}-1\right) \\
\hat{\rho}_{K}=\hat{\rho}_{F}=0
\end{gathered}
$$


Equation (33) and Equation (34) equal implies that the steady-state ratio of the price of food to manufactures will be:

$$
P_{F}^{*}=\left(\frac{\gamma_{K}-1}{\gamma_{K}}\right)\left(\frac{\gamma_{F}}{\gamma_{F}-1}\right)\left(\frac{a_{K F}}{a_{K K}}\right)
$$

The Southern terms of trade are positively related to the Northern markup, inversely related to the markup in the South, positively related to the proportion of the available capital goods utilized in the South, and inversely related to the proportion of the available capital goods utilized in the North. For the South, if either the mark-up or prices goes up, profit goes up. But in Classical equilibrium, which is defined by holding the profit rate constant, an increase in mark-up must be counteracted by lower price level (here terms of trade) to hold the profit rate constant.

Symmetrically, for the North, an increase in its mark-up will have to be counter-balanced by a lower Northern relative price (inverse of $P_{F}$ ) to maintain a constant profit rate in the long-period equilibrium. This result is only meaningful outside of the narrow but conventional world of constant returns-and-cost minimization because, then and only then, are the terms $\gamma_{K}$ and $\gamma_{F}$ different from unity. Equation (48) is the equilibrium terms of trade in a world economy where a pure profit is generated in both regions.

But it is only the zero surplus economy that is the home of balanced growth. In contrast, with symmetric decreasing returns, even with cost minimization, the equilibrium rate of growth of wages in the North will not be zero. Instead, from (43), a proportional relationship exists between variations in the Northern wage rate and variations in the Northern markup; specifically

$\hat{w}_{K}=1 /\left(\theta_{K K} \varepsilon_{w}^{K K}+\theta_{L K} \varepsilon_{w}^{L K}\right) \hat{\gamma}_{K}$. Correspondingly, the nonzero value of $\hat{w}_{K}$ plus the diminishing returns condition that implies $\varepsilon_{K}^{L K}>0$ means that Northern output will not grow at the natural rate [see (41)]. Balanced growth is not the norm for the system in the long-period, and the markup terms will continue to vary to maintain the international uniformity of rates of profit.

Finally, consider the Classical long period equilibrium for a model characterized by capital accumulation in a manner similar to the discussion in Section 3 above. To solve the full system with a capital accumulation equation of the type given in (19) necessitates relinquishing the exogenous employment growth in the North; $\hat{L}_{N}$ must be solved endogenously. The solution is similar to that for the model of Section 3 with capital accumulation. The general solution is presented in Equations (49)-(56).

Expressions (49) and (50) are identical to Equation (20) and Equation (21) of the model of the previous section with accumulation. Equation (51) is similar to (23), except the separation of national labor forces breaks the link between food production and employment growth in capital goods production. There is still an inverse relationship between Northern wage movements and employment growth in the North. The positive relationship between capital accumulation and Northern employment is maintained, again, as long as economies of scale are 
not sufficiently strong to make the coefficient on $\hat{K}^{*}$ negative.

$$
\begin{aligned}
& \hat{\gamma}_{K}^{*}=\frac{\left\{\left(\theta_{L K} \varepsilon_{K}^{L K}+\theta_{K K} \varepsilon_{K}^{K K}\right)-\left(\theta_{L K} \varepsilon_{w}^{L K}+\theta_{K K} \varepsilon_{w}^{K K}+\theta_{L K}\right) \frac{\varepsilon_{K}^{K K}}{\varepsilon_{w}^{K K}}\right\} \hat{K}^{*}}{\left\{\left(\theta_{L K} \varepsilon_{w}^{L K}+\theta_{K K} \varepsilon_{w}^{K K}+\theta_{L K}\right) \frac{R_{K}}{\varepsilon_{w}^{K K}}+1\right\}} \\
& \hat{W}_{K}^{*}=\left(\frac{R_{K}}{\varepsilon_{W}^{K K}}\right) \hat{\gamma}_{K}^{*}-\left(\frac{\varepsilon_{K}^{K K}}{\varepsilon_{W}^{K K}}\right) \hat{K}^{*} \\
& \hat{L}_{K}^{*}=\left(1+\varepsilon_{K}^{L K}\right) \hat{K}^{*}+\varepsilon_{W}^{L K} \hat{W}_{K}^{*} \\
& \hat{F}^{*}=\frac{1}{\{H\}} \cdot\left\{\left[R_{F}\left(\theta_{K F} \varepsilon_{W}^{K F}+\theta_{L F}-1\right)+\varepsilon_{F}^{K F}\right]\left[\left(1-A \varepsilon_{K}^{K K}\right) K+A \varepsilon_{K}^{K K} \hat{W}_{K}^{*}\right]\right\} \\
& \hat{P}_{F}^{*}=\frac{1}{\{H\}} \cdot\left\{\left[\left(1-\varepsilon_{W}^{K F}\right)-R_{F} \theta_{K F} \varepsilon_{F}^{K F}\right]\left[\left(1-A \varepsilon_{K}^{K K}\right) \hat{K}^{*}+A \varepsilon_{K}^{K K} \hat{W}_{K}^{*}\right]\right\} \\
& \hat{L}_{F}^{*}=\frac{1}{\{H\}} \cdot\left\{\left[\varepsilon_{W}^{K F}\left(1+\varepsilon_{F}^{L F}\right)+\varepsilon_{W}^{L F}\left(1-\varepsilon_{W}^{K F}\right)+R_{F}\left(1+\varepsilon_{F}^{L F}\right)\left(\theta_{K F} \varepsilon_{W}^{K F}+\theta_{L F}-1\right)\right.\right. \\
& \left.\left.-\varepsilon_{W}^{L F} \theta_{K F} \varepsilon_{F}^{K F}\right] \cdot\left[\left(1-A \varepsilon_{K}^{K K}\right) \hat{K}^{*}+A \varepsilon_{K}^{K K} \hat{W}_{K}^{*}\right]\right\} \\
& \hat{\gamma}_{F}^{*}=\frac{1}{\{H\}} \cdot\left\{-\left[\varepsilon_{F}^{K F^{2}} \theta_{K F}+\left(1-\varepsilon_{W}^{K F}\right)\left(\theta_{K F} \varepsilon_{W}^{K F}+\theta_{L F}-1\right)\right]\right. \\
& \left.\cdot\left[\left(1-A \varepsilon_{K}^{K K}\right) \hat{K}^{*}+A \varepsilon_{K}^{K K} \hat{W}_{K}^{*}\right]\right\} \\
& \{H\} \equiv\left(1-\varepsilon_{F}^{K F 2}\right)\left[R_{F}\left(\theta_{K F} \varepsilon_{W}^{K F}+\theta_{L F}-1\right)\right]+\varepsilon_{F}^{K F}\left(1+\varepsilon_{F}^{K F}\right) \\
& -\varepsilon_{F}^{K F}\left[R_{F} \theta_{K F} \varepsilon_{F}^{K F}-\left(1-\varepsilon_{W}^{K F}\right)\right]
\end{aligned}
$$

The steady-state rate of capital accumulation is the global engine of growth, just as it was the internal engine of growth in the model of Section 3 above. Equation (53) provides the expression for the long-period terms of trade, which could be perpetually deteriorating or improving for the South. There is no inherent predisposition toward either outcome; it depends entirely on the particular mix of parameters-contingent on both scale and substitution effects.

Let us consider some special cases to understand the implications of different returns to scale on key variables. Homothetic production functions would imply $\varepsilon_{F}^{L F}=\varepsilon_{F}^{K F}$ and $\varepsilon_{K}^{L K}=\varepsilon_{K}^{K K} \cdot{ }^{15}$ Under this assumption we consider two types of elasticity of input substitution: a situation of almost zero elasticity and a situation of unit elasticity ${ }^{16}$.

The effect of capital growth on Northern wages and Northern employment is found to depend only on the returns to scale in the capital sector, while the effect on terms of trade, food production and Southern employment depend on the returns to scale in both capital and food sectors.

Capital growth has positive effect on Northern wages when there is IRS in the capital sector, a negative effect on Northern wages with DRS in the capital sector,

\footnotetext{
${ }^{15}$ Again this is similar to [18].

${ }^{16}$ The form of the solutions under these special cases is provided in the Appendix.
} 
and no effect on wages when CRS in capital sector. The effects out of constant returns are magnified by a lower elasticity of input substitution.

Increased production in the capital sector is accompanied by a proportionately higher growth in labor demand when production in capital sector is characterized by DRS or weak IRS $\left(\varepsilon_{K}^{L K}>-1\right)$ and by a proportionately lower growth of labor demand when the capital sector is characterized by strong IRS $\left(\varepsilon_{K}^{L K}<-1\right)$. The effect is reinforced by the movement of wages, although this effect gets weaker as elasticity of substitution becomes weaker.

Therefore, with a low elasticity of input substitution in the capital sector, the effect of capital growth is contained mainly on the effect on Northern wages. Whereas with a higher input elasticity, there is greater spillover of the effect onto Northern employment as well.

Greater availability of Northern capital has an effect on terms-of-trade, food production and Southern employment (with Southern real wages assumed to be fixed). Growth of capital has an effect on Southern variables through 2 channels: 1) the direct effect of greater abundance of capital input and 2) the indirect effect of capital growth on Northern wages which in turn impacts terms-of-trade and hence Southern production and employment.

If we first focus on understanding the direct effect of growth of Northern capital, ignoring for the time being the indirect Northern wage effect, we find the following. The terms-of-trade for the South improve if both food and capital sectors experience increasing returns or both experience decreasing returns to scale. On the contrary, the terms of trade for the South worsen if one sector is characterized by increasing returns while the other is characterized by decreasing returns to scale. A greater possibility of substitutability of inputs in the food sector reduces the strength of the effect of capital growth on terms-of-trade.

Let us next consider the indirect effect of capital growth on Northern wages: increasing returns in capital raises Northern wages while decreasing returns to scale in capital lowers Northern wages. However, the wage movement gets multiplied with the returns-to-scale of the capital sector, making the impact on Southern terms of trade negative in both cases. With close to zero substitutability of inputs in the capital sector, the wage effect dominates the direct capital effect explained above, while with a greater degree of substitutability, the wage effect together with the direct capital effect determines the net effect of capital growth on the Southern terms of trade. The movement of Southern terms of trade has direct implications for real wages in the North and for nominal wages in the South given that real wages are constant in the South. These outcomes are summarized in Table 3.

If decreasing returns to scale prevail in both sectors, the relative price of food rises implying nominal wages in South rises, while nominal wages fall in the North. In real terms the real wages in North fall while in South it remains constant. If manufacturing switches to IRS while agriculture remains DRS, worsening Southern terms-of-trade translate into lower nominal wages for Southern workers while IRS in manufacturing ensures higher real wages in the North. 
Table 3. Effect of capital growth on real-wages and terms-of-trade in north-south model.

\begin{tabular}{lll}
\hline \multicolumn{1}{c}{ DRS in Manufacturing } & \multicolumn{1}{c}{ IRS in Manufacturing } \\
\hline - Southern TOT improves & • Southern TOT worsens \\
- Nominal wage in South increases & - Nominal wage in South declines \\
DRS in Food & - Nominal wage in North declines & - Northern nominal wage increases \\
- Real wage in South constant & - Real wage in South constant \\
- Real wage in North worsens & - Real wage in North improves \\
- Southern TOT worsens & - Southern TOT improves \\
- Nominal wage in South increases & - Nominal wage in South increases \\
- Nominal wage in North declines & - Nominal wage in North increases \\
- Real wage in South constant & - Real wage in South constant \\
- Real wage movement in North & - Real wage movement in North \\
& ambiguous & ambiguous \\
\hline
\end{tabular}

With IRS in both sectors, the relative price of food rises; hence the nominal wage rises in the South while direction of movement of real wage in North is ambiguous. Also, in the unlikely combination of DRS in manufacturing and IRS in agriculture, Food price falls, Southern nominal wage falls while in North nominal wages fall with direction of real wage being ambiguous. Since employment in both North and in South are also endogenous to this model, the movement of real wages does not directly lend itself to interpretations about inequality between North and South.

Only with constant returns with cost minimization in both regions do the balanced growth results reemerge. Under those conditions, $\hat{\gamma}_{K}^{*}=\hat{\gamma}_{F}^{*}=\hat{w}_{K}^{*}=\hat{P}_{K}^{*}=0$ and $\hat{L}_{K}^{*}=\hat{F}^{*}=\hat{L}_{F}^{*}=\hat{K}^{*}$. Departure from either constant returns or cost minimization eliminates this familiar characterization of equilibrium growth. It is a familiar characterization but, as should be fully evident now, an intensely narrow characterization given the range of possibilities engendered by an economy with a pure surplus. Our paper accomplishes broadening the equilibrium characterization to include less restrictive returns to scale scenarios.

\section{Conclusions}

This paper proposes a general framework of the theory of trade and distribution under variable returns to scale and uncovers several interesting results that cannot be captured under the narrow assumption of constant returns to scale. To characterize long period equilibrium, we incorporate capital accumulation and use the Classical definition of long-period equilibrium as profit rates being equalized across sectors: a definition that is appropriate in handling non-constant returns resulting in non-zero surplus.

In the single country model, as well as the North-South model with capital accumulation, our results indicate that full employment is not an automatic outcome in long-term equilibrium. The Northern wage rate is found to respond positively to production levels under increasing returns to scale in the capital sector and conversely under decreasing returns to scale.

We find that expanded food production and capital accumulation generate 
growth in employment in the respective sectors under diminishing or constant returns. The positive relationship can be maintained under increasing returns as long as economies of scale are not too strong.

Furthermore, we find that balanced growth as a characterization of the long-period equilibrium holds only under constant returns to scale and not for the broader spectrum of variable returns to scale, raising the possibility that steady state equilibrium may not be an appropriate name for this long period equilibrium. The above results, that predict the interrelationships between variables change as returns to scale change, are obscured if one makes the assumption of solely constant returns to scale.

In the closed economy scenario the relative price of food improves with greater food production under diminishing returns in the food sector but deteriorates under increasing returns. In the North-South scenario, capital growth improves Southern terms of trade if both North and South have similar returns to scale and worsens if the returns to scale are dissimilar. Northern wage movements also caused by capital growth tend to deteriorate Southern terms of trade irrespective of the degree of returns to scale of the two sectors. The net effect of capital growth on Southern terms of trade depends on the relative strengths of the capital availability and Northern wage effects. A greater elasticity of input substitution in the food sector makes the capital availability effect weaker while greater elasticity of input substitution in the capital sector makes the Northern wage effect weaker.

Given that Southern TOT represents the relative price of food, with the price of manufactures being normalized to unity, conditions that lead to deterioration of Southern terms of trade tend to improve the real wages in North while in South nominal wages move to keep the real wages constant. However, given that neither the North nor the South is characterized by full employment conditions, real wage movements cannot directly be interpreted as changes in inequality.

Endogenous technological change using Classical equilibrium would be the direction of future research within this broader paradigm of generalized returns to scale. If initially both sectors are characterized by decreasing returns to scale, this would be accompanied by a better term of trade and higher nominal wages for the South but lower nominal and real wages for North. If manufacturing eventually switches to increasing returns technology, the worsening of terms of trade for the South implies higher real and nominal wages for the North but lower nominal wages for the South. Hence while the Northern economy would target a move towards increasing returns in the manufacturing sector to attain higher wages for its workers, this would be followed by a similar desire to move toward increasing returns in the food sector by the South to attain better terms of trade and higher wages in South.

\section{Conflicts of Interest}

The authors declare no conflicts of interest regarding the publication of this paper. 


\section{References}

[1] Sraffa, P. (1960) Production of Commodities by Means of Commodities. Cambridge University Press, Cambridge.

[2] Garegnani, P. (2007) Professor Samuelson on Sraffa and the Classical Economists. The European Journal of the History of Economic Thought, 14, 181-242. https://doi.org/10.1080/09672560701327919

[3] Garegnani, P. (2007) Professor Foley and Classical Policy Analysis. Review of Political Economy, 19, 221-242. https://doi.org/10.1080/09538250701256805

[4] Garegnani, P. (2005) Capital and Intertemporal Equilibria: A Reply to Mandler. Metroeconomica, 56, 411-437. https://doi.org/10.1111/j.1467-999X.2005.00223.X

[5] Garegnani, P. (2002) Misunderstanding Classical Economics? A Reply to Blaug. History of Political Economy, 34, 241-254. https://doi.org/10.1215/00182702-34-1-241

[6] Garegnani, P. (1998) Sraffa: The Theoretical World of the "Old Classical Economists”. The European Journal of the History of Economic Thought, 5, 415-429. https://doi.org/10.1080/10427719800000043

[7] Solow, R.M. (1956) A Contribution to the Theory of Economic Growth. Quarterly Journal of Economics, 70, 65-94. https://doi.org/10.2307/1884513

[8] Lewis, W.A. (1954) Economic Development with Unlimited Supplies of Labor. The Manchester School, 22, 139-191. https://doi.org/10.1111/j.1467-9957.1954.tb00021.x

[9] Findlay, R. (1980) The Terms of Trade and Equilibrium Growth in the World-Economy. American Economic Review, 70, 291-299.

[10] Semmler, W. (1984) Competition, Monopoly, and Differential Profit Rates. Columbia University Press, New York. https://doi.org/10.7312/semm90706

[11] Clifton, J. (1977) Competition and the Evolution of the Capitalist Mode of Production. Cambridge Journal of Economics, 1, 137-151.

[12] Clifton, J. (1983) Administered Prices in the Context of Capitalist Development. Contributions to Political Economy, 2, 23-38. https://doi.org/10.1093/oxfordjournals.cpe.a035662

[13] Harris, D.J. (1988) On the Classical Theory of Competition. Canadian Journal of Economics, 12, 139-167. https://doi.org/10.1093/oxfordjournals.cje.a035043

[14] White, G. (2011) Degrees of Competition, the Rate of Return and Growth from a Classical/Sraffian Perspective. University of Sydney Economics, Working Paper Series 2011-3, Sydney.

[15] Tsoulfidis, L. (2011) Classical vs. Neoclassical Conceptions of Competition. MPRA Paper 43999, University Library of Munich, Munich.

[16] Townsend, R.F., Kirsten, J. and Vink, N. (1998) Farm Size, Productivity and Returns to Scale in Agriculture Revisited: A Case Study of Wine Producers in South Africa. Agricultural Economics, 19, 175-180. https://doi.org/10.1016/S0169-5150(98)00033-4

[17] Podinovski, V.V. (2004) Local and Global Returns to Scale in Performance Measurement. Journal of the Operational Research Society, 55, 170-178. https://doi.org/10.1057/palgrave.jors.2601680

[18] Mayer, W. (1974) Variable Returns to Scale in General Equilibrium Theory: A Comment. International Economic Review, 15, 225-335. https://doi.org/10.2307/2526102

[19] Kemp, M.C. and Schweinberger, A.G. (1991) Variable Returns to Scale, Non-Uniqueness 
of Equilibrium and the Gains from International Trade. Review of Economic Studies, 58, 807-816. https://doi.org/10.2307/2297835

[20] Choi, J.-Y. and Yu, E.S.H. (2002) External Economies in the International Trade Theory: A Survey. Review of International Economics, 10, 708-728.

https://doi.org/10.1111/1467-9396.t01-1-00360

[21] Fujiwara, K. and Shimomura, K. (2005) A Factor Endowment Theory of International Trade under Imperfect Competition and Increasing Returns. The Canadian Journal of Economics, 38, 273-289. https://doi.org/10.1111/j.0008-4085.2005.00280.x

[22] Blecker, R. (2012) Stolper-Samuelson Revisited: Trade and Distribution with Oligopolistic Profits. Metroeconomica, 63, 569-598.

https://doi.org/10.1111/j.1467-999X.2012.04160.x

[23] Melitz, M.J. (2003) The Impact of Trade on Intra-Industry Reallocations and Aggregate Industry Productivity. Econometrica, 71, 1695-1725. https://doi.org/10.1111/1468-0262.00467

[24] Melitz, M.J. and Ottaviano, G.I.P. (2008) Market Size, Trade, and Productivity. Review of Economic Studies, 75, 295-316. https://doi.org/10.1111/j.1467-937X.2007.00463.x

[25] De Loecker, J. and Warzynski, F. (2012) Markups and Firm-Level Export Status. American Economic Review, 102, 2437-2471. https://doi.org/10.1257/aer.102.6.2437

[26] Davis, D.R. and Harrigan, J. (2011) Good Jobs, Bad Jobs, and Trade Liberalization. Journal of International Economics, 84, 26-36. https://doi.org/10.1016/j.jinteco.2011.03.005

[27] Helpman, E., Itskhoki, O. and Redding, S. (2011) Trade and Labor Market Outcomes. NBER Working Paper No. 16662. https://doi.org/10.3386/w16662

[28] Egger, H. and Kreickemeier, U. (2012) Fairness, Trade, and Inequality. Journal of International Economics, 86, 184-196. https://doi.org/10.1016/j.jinteco.2011.10.002

[29] Egger, H., Egger, P. and Kreickemeier, U. (2012) Trade, Wages, and Profits. European Economic Review, 64, 332-350. https://doi.org/10.1016/j.euroecorev.2013.09.008

[30] Amiti, M. and Davis, D.R. (2012) Trade, Firms, and Wages: Theory and Evidence. Review of Economic Studies, 79, 1-36. https://doi.org/10.1093/restud/rdr016

[31] Bernard, A.B., Redding, S.J. and Schott, P.K. (2007) Comparative Advantage and Heterogeneous Firms. Review of Economic Studies, 74, 31-66. https://doi.org/10.1111/j.1467-937X.2007.00413.x

[32] Atallah, G. and Semenov, A. (2018) Technological Progress and Sectoral Shares. Australian Economic Papers, 57, 142-153. https://doi.org/10.1111/1467-8454.12112

[33] Oniki, H. and Uzawa, H. (1965) Patterns of Trade and Investment in a Dynamic Model of International Trade. Review of Economic Studies, 32, 15-38. https://doi.org/10.2307/2296328

[34] Stiglitz, J.E. (1970) Factor Price Equalization in a Dynamic Economy. Journal of Political Economy, 78, 456-488. https://doi.org/10.1086/259644

[35] Baxter, M. (1992) Fiscal Policy, Specialization, and Trade in the Two-Sector Model: The Return of Ricardo? Journal of Political Economy, 100, 713-744. https://doi.org/10.1086/261837

[36] Nishimura, K. and Shimomura, K. (2002) Trade and Indeterminacy in a Dynamic General Equilibrium Model. Journal of Economic Theory, 105, 244-260. https://doi.org/10.1006/jeth.2001.2892 
[37] Darity, W. and Davis, L.S. (2005) Growth, Trade and Uneven Development. Cambridge Journal of Economics, 29, 141-170. https://doi.org/10.1093/cje/bei003

[38] Burgstaller, A. and Saavedra-Rivano, N. (1984) Capital Mobility and Growth in a North-South Model. Journal of Development Economics, 15, 213-237. https://doi.org/10.1016/0304-3878(84)90017-8

[39] Burgstaller, A. (1985) North-South Trade and Capital Flows in a Ricardian Model of Accumulation. Journal of International Economics, 18, 241-260. https://doi.org/10.1016/0022-1996(85)90054-6

[40] Darity, W. (1990) The Fundamental Determinants of the Terms of Trade Reconsidered: Long-Run and Long-Period Equilibrium. American Economic Review, 80, 816-827.

[41] Ruffin, R. (1979) Growth and the Long-Run Theory of International Capital Movements. American Economic Review, 69, 832-842.

[42] Smith, M.A.M. (1977) Capital Accumulation in the Open Two-Sector Economy. Economic Journal, 87, 273-282. https://doi.org/10.2307/2232086

[43] Jones, R.W. (1965) The Structure of Simple General Equilibrium Models. Journal of Political Economy, 73, 557-572. https://doi.org/10.1086/259084

[44] Ros, J. and Skott, P. (1998) Dynamic Effects of Trade Liberalization and Currency Overvaluation under Conditions of Increasing Returns. The Manchester School of Economic \& Social Studies, 66, 466-489. https://doi.org/10.1111/1467-9957.00118

[45] Skott, P. and Larudee, M. (1998) Uneven Development and the Liberalisation of Trade and Capital Flows: The Case of Mexico. Cambridge Journal of Economics, 22, 277-295. https://doi.org/10.1093/oxfordjournals.cje.a013717

[46] Steedman, I. (1979) Introductory Essay. In: Steedman, I., Ed., Fundamental Issues in Trade Theory, St. Martin's Press, New York, 1-14. https://doi.org/10.1007/978-1-349-04378-1

[47] Steedman, I. (1979) Fundamental Issues in Trade Theory. St. Martin's Press, New York. https://doi.org/10.1007/978-1-349-04378-1

[48] Kalecki, M. (1971) Selected Essays on the Dynamics of the Capitalist Economy. Cambridge University Press, Cambridge. 


\section{Appendix}

In this appendix, we assume Homothetic Production functions: $\varepsilon_{K}^{K K}=\varepsilon_{K}^{L K} \equiv \varepsilon_{K} ; \varepsilon_{F}^{K F}=\varepsilon_{F}^{L F} \equiv \varepsilon_{F}$

Special Case A: Unit elasticity: $\varepsilon_{W}^{K K}=1 ; \quad \varepsilon_{W}^{L K}=-1 ; \quad \varepsilon_{W}^{K F}=1 ; \quad \varepsilon_{W}^{L F}=-1$

1) $\hat{W}_{K}^{*}=\left(\frac{R_{K}}{1}\right) \hat{\gamma}_{K}^{*}-\left(\frac{\varepsilon_{K}}{1}\right) \hat{K}^{*}$

2) $\hat{L}_{K}^{*}=\left(1+\varepsilon_{K}\right) \hat{K}^{*}-\hat{W}_{K}^{*}$

3) $\hat{F}^{*}=\frac{1}{\{H\}} \cdot\left\{\left[\varepsilon_{F}\right]\left[\left(1-A \varepsilon_{K}\right) \hat{K}^{*}+A \varepsilon_{K} \hat{W}_{K}^{*}\right]\right\}$

4) $\hat{P}_{F}^{*}=\frac{1}{\{H\}} \cdot\left\{\left[-R_{F} \theta_{K F} \varepsilon_{F}\right]\left[\left(1-A \varepsilon_{K}\right) \hat{K}^{*}+A \varepsilon_{K} \hat{W}_{K}^{*}\right]\right\}$

5) $\hat{L}_{F}^{*}=\frac{1}{\{H\}} \cdot\left\{\left[\left(1+\varepsilon_{F}\right)+\theta_{K F} \varepsilon_{F}\right] \cdot\left[\left(1-A \varepsilon_{K}\right) \hat{K}^{*}+A \varepsilon_{K} \hat{W}_{K}^{*}\right]\right\}$

6) $\{H\} \equiv \varepsilon_{F}+\varepsilon_{F}^{2}\left[1-R_{F} \theta_{K F}\right] ;\{H\}>0$ iff $\varepsilon_{F}^{2}>\varepsilon_{F} /\left[R_{F} \theta_{K F}-1\right]$

Special Case B: Close to zero elasticity: $\varepsilon_{W}^{K K} \rightarrow 0 ; \varepsilon_{W}^{L K} \rightarrow 0 ; \varepsilon_{W}^{K F} \rightarrow 0$; $\varepsilon_{W}^{L F} \rightarrow 0$
7) $\hat{W}_{K}^{*}=-\left(\frac{\varepsilon_{K}}{\varepsilon_{W}^{K K}}\right) \hat{K}^{*}$
8) $\hat{L}_{K}^{*}=\left(1+\varepsilon_{K}\right) \hat{K}^{*}$
9) $\hat{F}^{*}=\frac{1}{\{H\}} \cdot\left\{\left[R_{F}\left(\theta_{L F}-1\right)+\varepsilon_{F}\right]\left[1+A \varepsilon_{K}\left(\hat{W}_{K}^{*}-\hat{K}^{*}\right)\right]\right\}$
10) $\hat{P}_{F}^{*}=\frac{1}{\{H\}} \cdot\left\{\left[1-R_{F} \theta_{K F} \varepsilon_{F}\right]\left[\left(1-A \varepsilon_{K}\right) \hat{K}^{*}+A \varepsilon_{K} \hat{W}_{K}^{*}\right]\right\}$
11) $\hat{L}_{F}^{*}=\frac{1}{\{H\}} \cdot\left\{\left[R_{F}\left(1+\varepsilon_{F}\right)\left(\theta_{L F}-1\right)\right] \cdot\left[\left(1-A \varepsilon_{K}\right) \hat{K}^{*}+A \varepsilon_{K} \hat{W}_{K}^{*}\right]\right\}$
12) $\{H\} \equiv\left(1+\varepsilon_{F}\right)^{2}-\left(1+R_{F} \theta_{K F}\right) ;\{H\}>0$ iff $\left(1+\varepsilon_{F}\right)^{2}>\left(1+R_{F} \theta_{K F}\right)$ 